\title{
Medical device-related pressure ulcers
}

This article was published in the following Dove Press journal:

Chronic Wound Care Management and Research

29 August 2016

Number of times this article has been viewed

\section{Joyce M Black' \\ Peggy Kalowes ${ }^{2}$}

'Adult Health and Illness Department, College of Nursing, University of Nebraska Medical Center, Omaha, NE, ${ }^{2}$ Nursing Research and Innovation, Long Beach Memorial Miller Children's \& Women's Hospital, Long Beach, CA, USA
Correspondence: Joyce Black College of Nursing, University of Nebraska Medical Center, 985330 Nebraska Medical Center, Omaha, NE 68198-5330, USA

Email jblack@unmc.edu
Abstract: Pressure ulcers from medical devices are common and can cause significant morbidity in patients of all ages. These pressure ulcers appear in the shape of the device and are most often found from the use of oxygen delivery devices. A hospital program designed to reduce the number of pressure ulcers from medical devices was successful. The program involved the development of a team that focused on skin, the results were then published for the staff to track their performance, and it was found that using foam dressings helped reduce the pressure from the device. The incidence of ulcers from medical devices has remained at zero at this hospital since this program was implemented.

Keywords: pressure ulcer, medical device related

\section{Introduction}

Pressure ulcers (PrUs) occur in soft tissues subjected to pressure. These soft tissues include tissues beneath medical devices used for monitoring or treatment. Medical device-related pressure ulcers (MDR PrUs) are becoming increasingly common in all settings and in all age groups and are often reported to various US state health departments and the National Database of Nursing Quality Indicators, revealing their incidence and seriousness. ${ }^{1}$ These ulcers can be more complicated than preventing usual PrUs because the device may be an essential diagnostic/therapeutic component of treatment. This review paper addresses the issues of PrUs beneath medical devices, presents options for prevention, and discusses a quality improvement (QI) project on MDR PrUs.

\section{Definition}

PrUs related to the use of medical devices are areas of localized injury to the skin or underlying tissue as a result of sustained pressure from a device ${ }^{2}$ (Figure 1). The soft tissue injury usually mimics the shape of the device, which is often rigid or secured with tight dressings. These PrUs can evolve into full-thickness PrUs due to the lack of adipose tissue in many of the areas of ulceration.

\section{Prevalence and incidence}

Little data have been published on PrUs from medical devices prior to 2000. In 1995, Davis et al reported that the incidence of occipital ulcers from cervical neck collars was $33 \%$ after 5 days of use and $44 \%$ when the collar was used over 5 days. Half of the ulcers were full thickness in this study. ${ }^{3}$ 


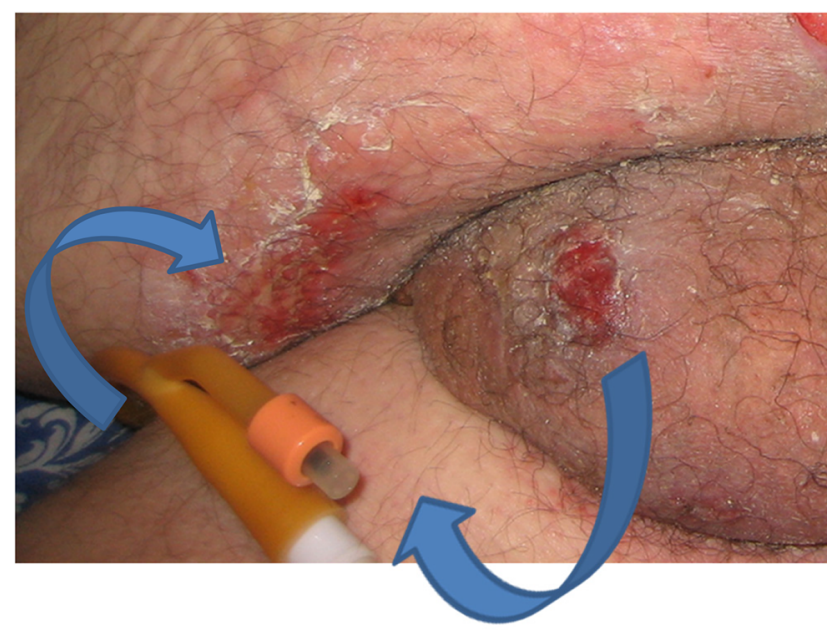

Figure I PrUs from the aspiration port and the balloon inflation port of an indwelling urinary catheter.

Abbreviation: PrUs, pressure ulcers.

Pediatric and neonatal PrUs can develop quickly due to the relative skin intolerance and physiological immaturity. In 2003, Curley et al published the first prospective data on medical device ulcers in children between the ages of 21 days and 8 years. The overall incidence of ulceration was $27 \%$, with $8 \%$ of children ulcerating from medical devices. The oxygen saturation probe, bi-level positive airway pressure mask, and endotracheal (ET) tubes were the most common devices (74\%). Preventive skin care included rotating the device, securing the ET tube closer to the mouth, and padding the skin under oxygen masks and the nasal bridge. ${ }^{4}$ The incidence of PrUs from continuous positive airway pressure devices in premature infants has been shown to be inversely correlated to the baby's gestational age. Babies $<28$ weeks of gestational age had a $90 \%$ PrU rate, compared to a $28 \%$ rate in babies 32 weeks and older. ${ }^{5}$ An integrative review of PrUs in children from medical devices listed more than 22 items associated with ulcers. The paper also reported that over a 2-year period, $0.5 \%(\mathrm{~N}=138)$ of pediatric patients of the 2,745 patients who were surveyed developed PrUs from medical devices. ${ }^{6}$

VanGilder et al reported on the prevalence of MDR PrUs from a large acute-care data set ( $\mathrm{N}=86,932$ patients). Among all the ulcers identified, 1,631 (9.1\%) were described as "device-related"; of these, 785 were acquired in the facility and 360 were full-thickness wounds. The most common anatomic locations for device-related ulcers were the ear $(20 \%)$, followed by the sacral/coccyx region, heel, and buttocks. ${ }^{7}$

In 2010, Black et al conducted a secondary analysis of eight quarterly incidence and prevalence studies in 2,079 patients in a Midwestern academic medical center. The overall PrU incidence was 5.4\%; 83 patients had 113 PrUs. Medical devices were the cause of $34.5 \%$ of the ulcers, which included stage 1 $(35 \%)$, stage $2(32 \%)$, stage $3(3 \%)$, deep tissue injury (6\%), and $24 \%$ unstageable ulcers. This seminal study found PrUs from medical devices on 14 body areas, predominately on the ears (35\%) and lower leg (11\%) and also reported that patients with medical devices were 2.4 times more likely to develop a PrU. ${ }^{2}$

Ayer et al reported on the prevalence over 11 months of MDR PrUs in a long-term acute-care setting. Data were reported on 304 facility-acquired PrUs; 44\% were from medical devices. Among these, $14 \%$ of ulcers were stage 1, $50 \%$ were stage 2 , and $36 \%$ were stage 3 PrUs. The ulcers were predominately on the heel and leg from boots, braces, or splints; on the face and neck from oxygen delivery devices; and on the perineum from urine or fecal drainage tubing. ${ }^{8}$

Some of the most extensive work was reported by Apold and Rudrych using data from the state of Minnesota. The greater majority (70.3\%) of PrUs from medical devices were on the head, face, or neck from cervical collars, oxygen tubing, and nasogastric tubes, and $20.3 \%$ were on the heel, ankle, or foot from immobilizers, support stockings, and boots. Nearly one-third of serious PrUs were those from medical devices. ${ }^{9}$

The frequency of ulceration varies by the type of device. Table 1 lists the ranges of incidence of PrUs by the medical devices. Devices for oxygen delivery and airway management have the highest reported PrUs (Figure 2). The priority placed on the airway often leads to tight securements, leading to ulcers from the securement device (eg, lip ulcers from tape to secure the ET tube), a tight device to maintain a seal (eg, facial ulcers from noninvasive positive pressure ventilation [NIPPV]), or tightening the tubing to prevent dislodgement (eg, tightening up the nasal cannula, leading to ulcers on the ears or face). Jatana et $\mathrm{l}^{10}$ reported that $13 \%$ of children with NIPPV develop ulcers and $6 \%$ of them develop necrosis of the columella.

\section{Characterization}

MDR PrUs should be differentiated from immobility-related hospital-acquired pressure ulcers (HAPUs) by examining the location of the HAPU; immobility-related HAPUs frequently occur over a bony prominence or tissue exposed to pressure from a support surface, and MDR HAPUs often mirror the shape and location of a medical device. Common risk factors for both HAPU categories included immobility, inactivity, sensory deficits, moisture, friction, shear, nutritional deficiencies, and/or poor oxygenation.

A unique aspect of MDR PrUs is a rigid plastic material used to construct several medical devices as the source of the external pressure. For example, devices for monitoring (arterial lines), prevention (heel off-loading devices), or 
Table I Incidence by type of device

\begin{tabular}{ll}
\hline Type of device & Frequency of ulceration \\
\hline Arterial line & Unreported \\
Cervical collars & $9.7 \%-23.7 \%{ }^{19,27} ; 33 \%$ ulceration in 5 days, \\
& $44 \%$ over 5 days ulceration increased $66 \%^{3}$ \\
& for every I day in the device \\
Ear & Up to $33 \%^{30}$
\end{tabular}

Abbreviations: EEG, electroencephalography; ET, endotracheal; CPAP, continuous positive airway pressure; BiPAP, bi-level positive airway pressure; PEG, percutaneous endoscopic gastrostomy.

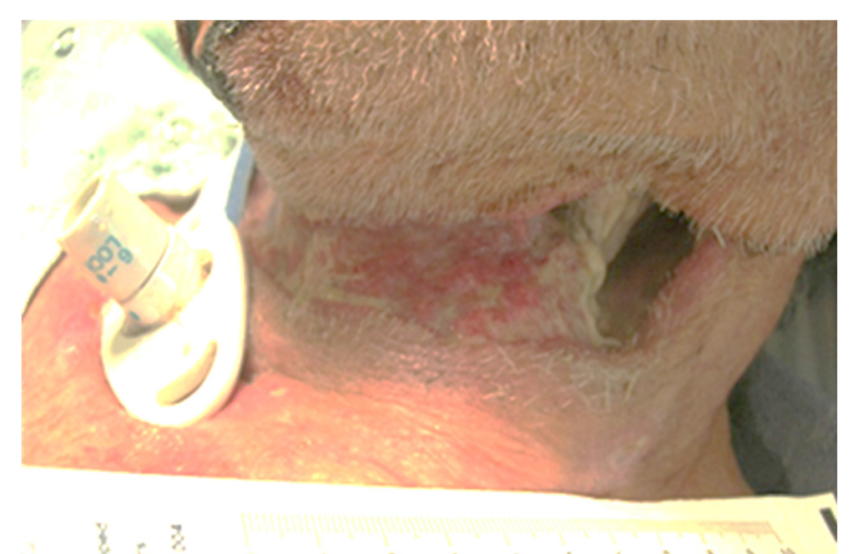

Figure 2 PrU from the securement straps around the neck in a patient with a tracheostomy.

Abbreviation: PrU, pressure ulcer.

treatment (continuous positive airway pressure masks, tracheostomy flange) often contain, in whole or in part, a hard plastic material. These materials exert pressure on the skin and lead to ulceration. Oxygen tubing has been recognized as a culprit in device ulcers for some time. A paper in 1972 called these ulcers a "bedsore of the ear" ${ }^{11}$ Some devices require securement to assure that they are not dislodged. Due to the securement, these devices seldom move, so shear forces are a less likely etiology. However, the securement straps or dressings can also exert pressure forces on the skin. Goodell performed an in vitro quantification of the pressure applied to the ear lobe by a pulse oximetry device and reported that $20.7 \mathrm{mmHg}$ pressure was applied to the lobe. This pressure was 0.24 pounds of force exerted over 0.3 square inches. ${ }^{12}$ This study does not show causality; however, it bears light on the intensity of pressure from some devices (Figure 3).

Patients with inflammatory diseases who develop edema from fluid resuscitation or inflammation can be injured from devices that become too tight. These issues are aggravated by inappropriate sizes or selections of products; when elastic stockings are applied that are too small, the patient may roll the stocking down to relieve pressure in the thigh. Microclimate (heat and humidity at the skin-device interface) also increases the risk of ulceration by creating maceration of skin and decreased tolerance of pressure.

\section{Appearance/staging}

PrUs from medical devices on the skin are characterized by changes in skin color or the appearance of an ulcer in the location of the medical device. When the ulcer involves the skin, these ulcers can be staged using the international PrU staging system. ${ }^{13}$ Ulcers on mucous membrane should not be staged. ${ }^{14}$ The anatomy of mucous membrane is not the same as skin and underlying soft tissue. Nonblanchable erythema is not visible on mucous membrane, and the base of the mucous membrane-covered tissue does not include muscle, tendon, ligaments, or bones. If cartilage is exposed, the ulcer can be staged as a stage 4 PrU..$^{15}$

\section{Experience in clinical practice}

Each of the many medical devices has unique aspects to the risks of ulceration and prevention plans. Any prevention plan

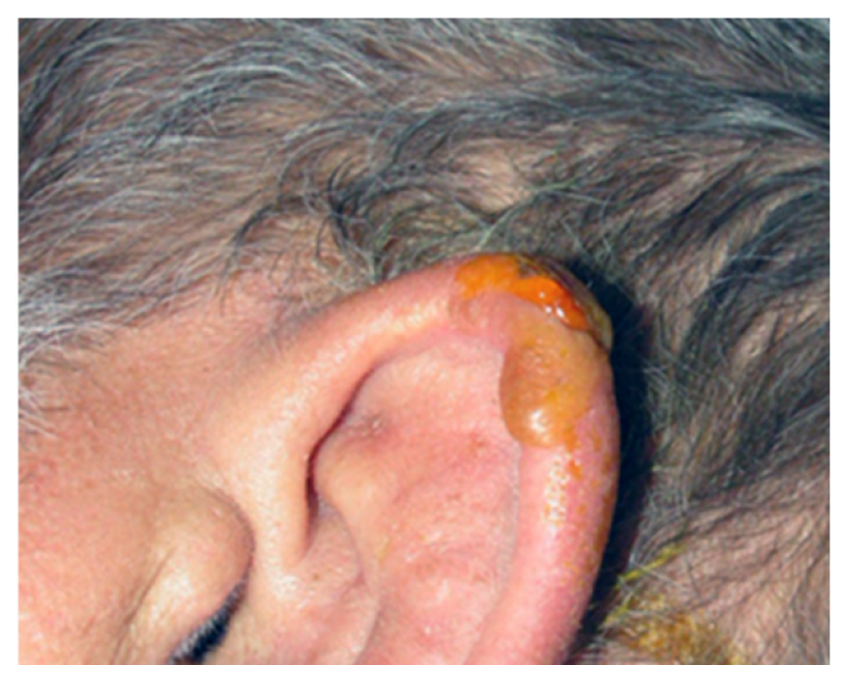

Figure $3 \mathrm{PrU}$ on the ear from an oxygen saturation probe. Abbreviation: $\mathrm{PrU}$, pressure ulcer. 
must begin with obtaining the correct size of the medical devices such as elastic stockings and heel off-loading devices. One-size-fits-all does not apply here.

Prevention plans must be comprehensive. ${ }^{16,17}$ These are presented in Table 2. Instituting measures to prevent harm from medical devices is paramount. Clinicians should be familiar with the medical devices that have been problematic in their health care system. Clinicians should be familiar with best practices that prevent MDR HAPUs for every medical device in use in their health care institution. ${ }^{18}$ Ulceration of the face and occiput from a neck collar is often due to fear of injury to the cervical spine if the collar is loosened and the patient moves

Table 2 Devices, issues, and suggested preventive practices

\begin{tabular}{lll}
\hline Devices & Issues leading to ulceration & Suggested methods to reduce risk \\
\hline Arterial line & Often placed prior to fluid resuscitation or edema & Loosen and retape tubing after 24-48 hours \\
Cervical collars & Need to stabilize cervical spine until ligamentous & Change to softer collar, ${ }^{32,39}$ pad collar at occiput, ${ }^{32,39}$ remove collar \\
& damage can be ruled out & daily to inspect, change pads to keep face/neck dry \\
Ear & $\begin{array}{l}\text { Tubing can be tightened to hold on the face. Ears } \\
\text { are thinly covered cartilage, so development of full }\end{array}$ & Pad areas of the face in contact with the tubing, use silicone oxygen \\
& thickness wounds occurs rapidly &
\end{tabular}

EEG leads Secured with glue for long-term reading of EEG to Use of EEG cap has reduced ulcerations diagnose epilepsy

Elastic stockings Often placed prior to fluid resuscitation or postoperative edema, used on patients with peripheral vascular disease

Fecal containment device Tubing too short to reach the side of the bed; ports of tube hidden in abdominal/perineal folds or under scrotum

Nasal cannula Device slips from the nares leading to tighter securement

NT/ET tube Need to secure device to prevent migration and accidental extubation

Nasogastric tubes

Noninvasive positive pressure masks (CPAP/ BiPAP)

PEG tubes

Pulse oximetry

Splints (wrist, leg)

Tracheostomy

Urinary catheter
Secured to cheek which puts tension on the tube in the nares

Urgency to place and secure tightly to prevent leaks, thin skin over bridge of nose

Stoma can enlarge and leak $\mathrm{HCl}$ acid on to abdomen

Oximetry clip used in hypoxic patients' ears to obtain Move device from ear to ear with each movement of the patient's reading; metal clip form of oximetry probe can exert head or body

high amounts of pressure on a small area of soft tissue

Often secured with wraps; doctors' orders may be unclear about removal of splint for skin assessment and care

Sutured tightly to secure airway; difficult to place dressings for padding under edematous tissue; ulcers develop in posterior neck folds

Secure with device that "floats" the tube in the nares, move the tube mask with silicone pads

$\mathrm{HCl}$ acid blockers for short-term use, skin protection with cyanoacrylate rather than dressings (dressings hold $\mathrm{HCl}$ acid on to the skin), rotate tube daily ${ }^{29}$

Rewrap device if edema develops, clarify orders to remove splint, observe for any signs of pressure and pad as needed

Work with doctors who place the tracheostomy to determine if suture can be removed at day 5, work with RTs to change ties with trach care, determine if RT or nurses will change securement
Measure to determine size, do not guess; remove twice daily to inspect skin on heels

Check location of tubing with each reposition, especially in the perineum, secure tubing to the bed leaving slack in the tubing

Pad the oxygen tubing or behind the ears, use silicone oxygen tubing

Secure tube with device that allows tube to move (avoid tape), ${ }^{37}$ move ET tube often, for example, with each turn in bed, cushioning the nasal ala with a hydrocolloid dressing reduced alar PrUs by $40 \%{ }^{34}$ and severity of wounds ${ }^{38}$ when the patient's head is turned, change to soft feeding tubes when able Pad the bridge of the nose and cheeks before placing, apply silicone dressings to the nare for infants in nasal CPAP, ${ }^{27}$ alternate between full face mask and smaller masks, ${ }^{28}$ rotate sites of CPAP, ${ }^{30,36}$ use face straps, use thicker, wider foam collar straps to pad skin, ${ }^{28}$ pad skin around stoma with thin, breathable dressings, check for ulcers beneath straps on each shift, look closely at securements in neck folds, find ties and move them daily, line entire neck with dressings, silver dressings reduced ulcers and peristomal skin injury ${ }^{18}$ Check location of tubing with each reposition, pad tubing ports, secure tubing to leg or lower abdomen (males) and leave slack in tubing

Abbreviations: EEG, electroencephalography; NT, nasotracheal tube; ET, endotracheal; PrUs, pressure ulcers; CPAP, continuous positive airway pressure; BiPAP, bi-level positive airway pressure; PEG, percutaneous endoscopic gastrostomy; MD, medical devices; RT, respiratory therapist.

Tubing too short to reach the side of the bed; ports of tube hidden in abdominal/perineal folds or under scrotum 
his head. ${ }^{19}$ Ulcers within tracheostomy stoma and beneath securement straps behind the neck need to be addressed by nurses and respiratory therapists. Using bundled interventions worked best. ${ }^{20}$ Ulcers from oxygen tubing were noted in patients who were not using oxygen prior to hospitalization. ${ }^{21}$ Ulceration of the heel and leg from elastic stockings, splints, or heel off-loading devices can occur when these devices are used in patients with compromised circulation. Deep tissue injury ulcers can develop quickly in these patients. Obese individuals are also at risk because tubes and medical devices can become compressed and hidden by large or deep skin folds.

Devices should be secured using tape and/or straps without tension. A number of studies have used dressings to pad the skin between the medical device and the skin and reduced ulcers. Due to the urgency of getting a secure airway and improving oxygenation or ventilation, it will be difficult to ask practitioners to wait while someone gets padding for the nose. Bundling the most common devices (eg, NIPPV masks) with preventive dressings will aid in getting the dressing on at the time of placement without delaying the process. ${ }^{22-24}$

Examining the skin is a crucial component of prevention, for example, changing the location or repositioning the device at routine intervals if possible. In one large study, $>74 \%$ of MDR PrUs were not identified until they were stage 3, 4, or unstageable. They also found that $63 \%$ of cases had no documentation of skin inspection, device removal, or pressure relief. ${ }^{9}$ Because many devices are on critically ill patients, examining the skin during the hand-off from nursing shift to nursing shift is an excellent way to have adequate help to hold the patient and examine the skin. The National Pressure Ulcer Advisory Panel created teaching posters on medical device ulcers. They can be found at npuap.org.

In 2012-13, a western US hospital had reduced the incidence of traditional PrUs on the sacrum, coccyx, and heel from $5.9 \%$ to $0.1 \%$ using an evidence-based (EB) SKIN (Support surface, Keep the patient moving, Incontinence management, Nutritional support) bundle ${ }^{22}$ including a five-layered foambordered dressing (Mepilex ${ }^{\circledR}$ Border Sacrum by Mölnlycke). Thus, the number of MDR PrUs became much more transparent. Using the Plan-Do-Study-Act model, an actionable plan to sustain improvement was developed. The first step was a small test of change, and preventive dressings were placed beneath all tracheostomy plates and other respiratory devices, particularly in the Neonatal Intensive Care Unit and Pediatric Intensive Care Unit (PICU). Results were apparent, and the ulcer rate decreased. So, an interdisciplinary team (Pediatric Clinical Nurse Specialist; Director of Nursing Research, Registered Nurses, Medical Doctors, Physical Therapist, and
Wound Program Director) was developed to design a broader performance improvement process. This team conducted a root cause analysis on the MDR PrUs $(\mathrm{N}=21)$. Using data on the location, the specific device involved, and compliance with existing SKIN bundle, a fact sheet was developed to aid in identification of these ulcers. EB interventions including frequent skin and device assessments, reducing the moisture interface, and padding the skin were included. To improve compliance, Long Beach Memorial Miller Children's \& Women's Hospital developed an interdisciplinary "Skin Surveillance Team" to review and discuss patients who are at high risk for skin breakdown. The team met every Tuesday and Thursday in General Pediatrics and on Monday and Thursday in Adult intensive care units. Patient and family education was also provided about preventive measures for the skin during the hospitalization and at home. A booklet was developed for the patient and family to explain how ulcers form and their role in prevention (Figure 4).

The Pressure Ulcer Prevention Model $^{\odot}$ with EB bundled skin prevention strategies was fully launched at the end of 2013 (Figure 5). Skin bundles are universal preventive precautions for all patients. Reported outcomes have been

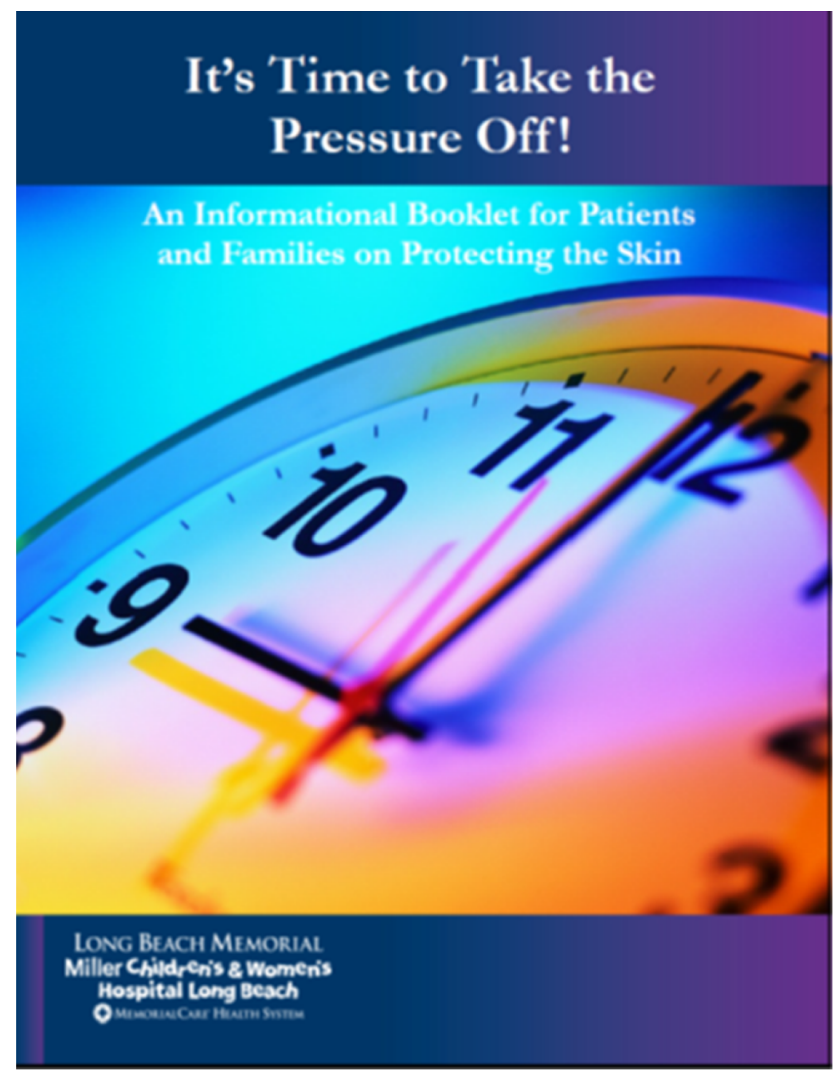

Figure 4 Patient information booklet cover on PrUs. Abbreviation: PrUs, pressure ulcers. 


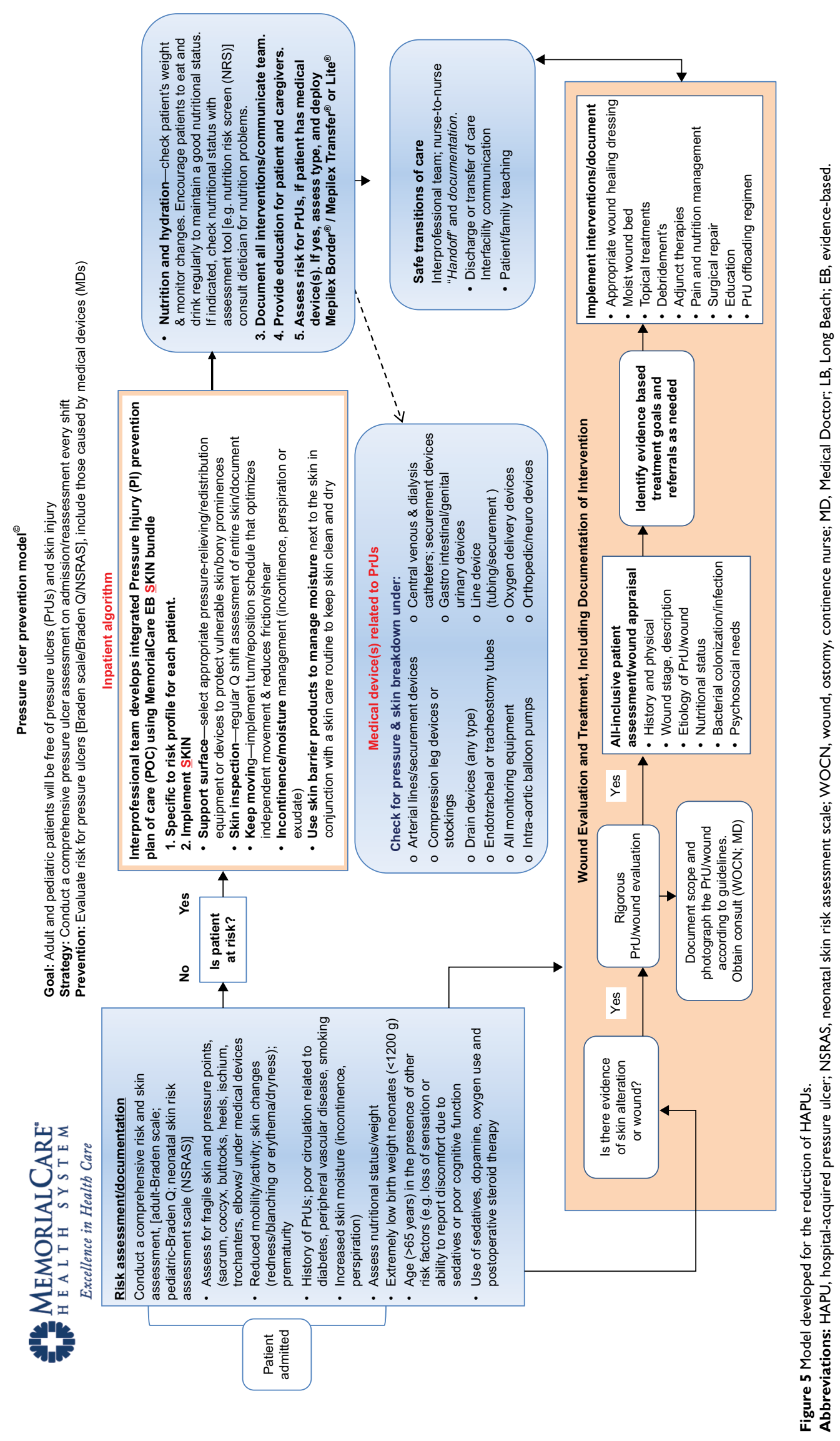


positive. ${ }^{24}$ Incidence and prevalence data, along with compliance with the Prevention Model $^{\circledR}$ Interventions, including MDR PrUs and SKIN bundle were tracked. Results show an absolute reduction of MDR PrUs from $0.06 \%$ incidence of stage 3+ MDR HAPUs per 1,000 patient days to zero in pediatrics (benchmark $0.0 \%-0.04 \%$ ). Among adults and elders, the cumulative incidence was reduced from $0.28 \%$ to zero with benchmark $0.05 \%-0.09 \%$ ). The hospital has sustained a "zero zone" incidence among adults and pediatric patients for PrUs overall, receiving a top performing, "Clinical Excellence Award" from CALNOC (the California Collaborative Alliance for Nursing Outcomes), for the past 3 years. Coyer reported that systematic and ongoing assessment of the patient's skin and risk for pressure injuries as well as implementation of tailored prevention measures are central to preventing pressure injuries in the critically ill. ${ }^{26}$ Visscher et al found similar results through the use of a team; the PrU rate in the PICU was 14.3/1,000 patient-days during the QI development and 3.7/1,000 patient-days after QI implementation $(\mathrm{P}<.05)$, achieving the aim of $50 \%$ reduction. The PICU rates of stages 1,2 , and 3 conventional and device-related PrUs also decreased after the QI intervention. However, they also reported that the PrU rate in the Neonatal Intensive Care Unit did not change significantly over time but remained at a mean of $0.9 / 1,000$ patient-days, primarily due to an increase in MDR PrUs associated with pulse oximeters, cannulas and positive pressure devices. ${ }^{25,36}$

Sustainability of the success of any program takes effort and requires executive and clinical leadership support, along with clinical staff commitment to "achieve and sustain zero". Long Beach Memorial Miller Children's \& Women's Hospital has instituted these interventions to achieve success:

- House wide interdisciplinary PrU prevention team

- Dashboards/visibility boards displaying data

- Quarterly house-wide PrU prevalence study, focus on MDR PrU prevention

- Use and auditing the electronic medical record for adherence to set group of preventive interventions used on all patients (often called a SKIN care bundle)

- Skin surveillance rounds/daily huddles in all units; skin champions

- Application of layered bordered foam dressings per protocol for cushioning beneath devices (Figure 6)

- Hourly intentional rounding (patient/family education) and daily staff safety huddles

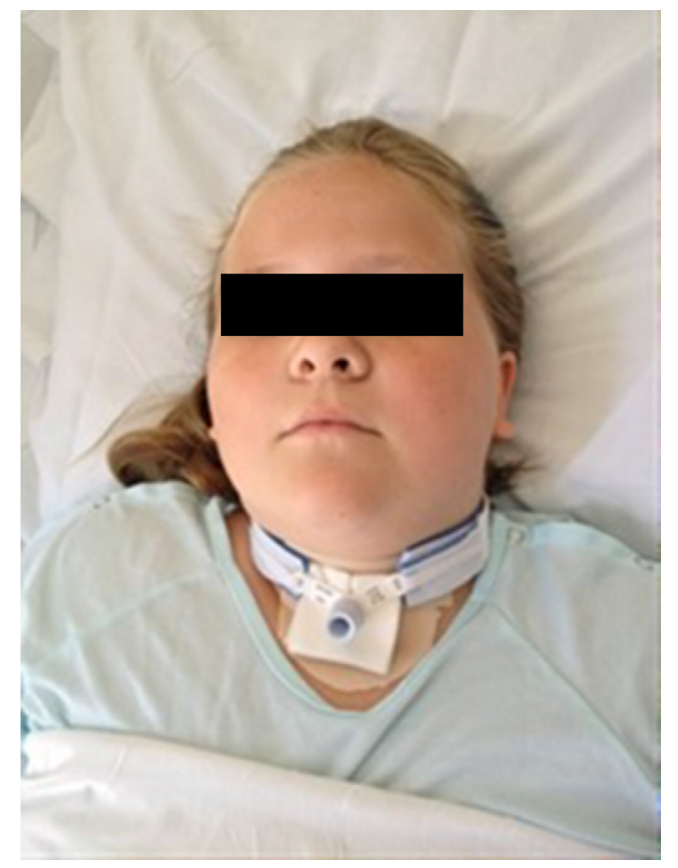

Figure 6 The use of thin dressings beneath a tracheostomy to reduce PrUs. Abbreviation: PrUs, pressure ulcers.

- Patient whiteboards to improve patient-centered communication, highlighting safety risks (PrUs; falls).

In order to examine the problem of MDR PrUs, hospital adverse event reporting programs should mandate the question "was this pressure ulcer due to a medical device?" If yes is answered, there should be a required field to document the specific medical device involved. A root cause analysis should be done to examine compliance with prevention plans. Focused educational initiatives can then be targeted to avoid specific HAPUs. Reporting of MDR HAPUs should specify the specific medical device and total device days. An opportunity exists for state and national groups to develop a registry in order to track the types of devices associated with PrU formation. Many devices in use today have not been redesigned and could benefit from future study on their design, safety features for high-risk patients, and improvement outcomes. ${ }^{30}$ There are limited data on the outcomes of these ulcers. Coyer reports on a small sample with only 4 of 11 healed at discharge. ${ }^{30,31}$

\section{Conclusion}

Although the pressure mechanism of soft tissue injury and staging is similar for immobility-related and devicerelated PrUs, risk assessment and the focus of prevention and management are different. Some simple interventions, 
such as padding high-risk areas, will reduce the intensity of the pressure. It is imperative that the skin be examined for early signs of pressure and that devices are chosen to fit the patient's body habitus.

\section{Disclosure}

Joyce M Black serves as a consultant to Molnlycke Health Care. The authors report no other conflicts of interest in this work.

\section{References}

1. Bergquist-Beringer S, Gajewski BJ, Davidson J. Pressure ulcer prevalence and incidence: report from the National Database of Nursing Quality Indicators ${ }^{\circledR}$ (NDNQI). In: Pieper B, with the National Pressure Ulcer Advisory Panel (NPUAP), editor. Pressure Ulcers: Prevalence, Incidence, and Implications for the Future. 2nd ed. Washington, DC: National Pressure Ulcer Advisory Panel (NPUAP); 2012:175-187.

2. Black JM, Cuddigan JE, Walko MA, Didier LA, Lander MJ, Kelpe MR. Medical device related pressure ulcers in hospitalized patients. Int Wound J. 2010;7(5):358-365.

3. Davis JW, Parks SN, Detlefs CL, Williams GG, Williams JL, Smith RW. Clearing the cervical spine in obtunded patients: the use of dynamic fluoroscopy. J Trauma. 1995;39(3):435-438.

4. Curley MA, Quigley SM, Lin M. Pressure ulcers in pediatric intensive care: incidence and associated factors. Pediatr Crit Care Med. 2003;4(3):284-290.

5. Fischer C, Bertelle V, Hohlfeld J, Forcada-Guex M, Stadelmann-Diaw C, Tolsa JF. Nasal trauma due to continuous positive airway pressure in neonates. Arch Dis Child Fetal Neonatal Ed. 2010;95(6):F447-F451.

6. Murray JS, Noonan C, Quigley S, Curley MA. Medical device-related hospital-acquired pressure ulcers in children: an integrative review. J Pediatr Nurs. 2013;28(6):585-595.

7. VanGilder C, Amlung S, Harrison P, Meyer S. Results of the 2008-2009 International Pressure Ulcer Prevalence Survey and a 3-year, acute care, unit-specific analysis. Ostomy Wound Manage. 2009;55(11):39-45.

8. Ayer M, Borchert K, Arnold-Long M. Device Related Hospital Acquired Pressure Ulcers in Long Term Acute Care Hospitals. WOCN Conference; 2011; New Orleans, LA.

9. Apold J, Rudrych D. Preventing device-related pressure ulcers: using data to guide statewide change. J Nurs Care Qual. 2012;27(1):28-34.

10. Jatana KR, Oplatek A, Stein M, Phillips G, Kang DR, Elmaraghy CA. Effects of nasal continuous positive airway pressure and cannula use in the neonatal intensive care unit setting. Arch Otolaryngol Head Neck Surg. 2010;136(3):287-291.

11. Gilston A. Bedsore of the ear. Lancet. 1972;16(2):1313.

12. Goodell T. An in vitro quantification of pressures exerted by earlobe pulse oximeter problems following reports of device-related pressure ulcers in ICU patients. Ostomy Wound Manage. 2012;58(11):30-34.

13. National Pressure Ulcer Advisory Panel (NPUAP). European Pressure Ulcer Advisory Panel (EPUAP), and Pan Pacific Pressure Injury Alliance (PPPIA). Prevention and Treatment of Pressure Ulcers: Clinical Practice Guideline. In: Haesler E, editor. Cambridge Media: Osborne Park, Western Australia; 2014.

14. Mucosal Pressure Ulcers: An NPUAP Position Statement. National Pressure Ulcer Advisory Panel. Washington DC; 2008.

15. Pressure Ulcers with Exposed Cartilage Are Stage IV Pressure Ulcers. National Pressure Ulcer Advisory Panel; 2012.

16. Dyer A. Ten top tips: preventing device-related pressure ulcers. Wounds Int. 2015;6(1):9-13.

17. Fletcher J. Device related pressure ulcers made easy. Wounds UK. 2012;8(2):1-4.
18. Samaniego I. A sore spot in pediatrics: risk factors for pressure ulcers. Dermatol Nurs. 2004;15:153-159.

19. Ackland HM, Cooper DJ, Malham GM, Kossmann T. Factors predicting cervical collar-related decubitus ulceration in major trauma patients. Spine. 2007;32(4):423-428.

20. Boesch RP, Myers C, Garrett T, et al. Prevention of tracheostomy-related pressure ulcers in children. Pediatrics. 2012;129(3):e792-e797.

21. Turjanica MA, Clark L, Martini C, Miller P, Turner B, Jones S. Incidence, correlates and interventions used for pressure ulcers of the ear. MedSurg Nurs. 2011;20(5):241-247.

22. Kuo CY, Wootten CT, Tylor DA, Werkhaven JA, Huffman KF, Goudy SL. Prevention of pressure ulcers after pediatric tracheotomy using a Mepilex Ag dressing. Laryngoscope. 2013;123(12):3201-3205.

23. Weng $M H$. The effect of protective treatment in reducing pressure ulcers for non-invasive ventilation patients. Intensive Crit Care Nurs. 2008;24(5):295-299.

24. Gibbons W, Shanks HT, Kleinhelter P, Jones P. Eliminating facilityacquired pressure ulcers at Ascension Health. Jt Comm J Qual Patient Saf. 2006;32:488-496.

25. Visscher M, King A, Nie AM, et al. A quality-improvement collaborative project to reduce pressure ulcers in PICUs. Pediatrics. 2013;131(6): e1950-e1960.

26. Coyer F, Gardner A, Doubrovsky A, et al. Reducing pressure injuries in critically ill patients by using a patient skin integrity care bundle (InSPiRE). Am J Crit Care. 2015;24(3):199-209.

27. Watts D, Abrahams E, MacMillan C, et al. Insult after injury: pressure ulcers in trauma patients. Orthop Nurs. 1998;17(4):84-91.

28. Jaul E. A prospective pilot study of atypical pressure ulcer presentation in a skilled geriatric nursing unit. Ostomy Wound Manage. 2011;57(2): 49-54.

29. Jones DJ, Braid GM, Wedzicha JA. Nasal masks for domiciliary positive pressure ventilation: patient usage and complications. Thorax. 1994;49(8):811-812.

30. Groeneveld A, Anderson M, Allen S, et al. The prevalence of pressure ulcers in a tertiary care pediatric and adult hospital. J Wound Ostomy Continence Nurs. 2004;31(3):108-120.

31. Coyer FM, Stotts, NA, Blackman VS. A prospective window into medical device-related pressure ulcers in intensive care. Int Wound J. 2014;11:656-664.

32. Powers J, Daniels D, McGuire C, Hilbish C. The incidence of skin breakdown associated with use of cervical collars. JTrauma Nurs. 2006;13(4): 198-200.

33. Noonan C, Quigley S, Curley M. Skin integrity in hospitalized infants and children: a prevalence survey. J Pediatr Nurs. 2006;21(6):445-453.

34. Günlemez A, Isken T, Gökalp AS, Türker G. Effect of silicone gel sheeting in nasal injury associated with nasal CPAP in preterm infants. Indian Pediatr. 2010;47(3):265-267.

35. Lemyze M, Mallat O, Nigeon O, et al. Rescue therapy by switching to total face mask after failure face make-delivered noninvasive ventilation in do-not-intubate patients in acute respiratory failure. Crit Care Med. 2013;41(2):481-488.

36. Newman K, McGrath J, Salyer J, Estes T, Jallo N, Bass T. A comparative effectiveness study of continuous positive airway pressure-related skin breakdown when using different nasal interfaces in the extremely low birth weight neonate. Appl Nurs Res. 2015;28(1):36-41.

37. Zaratkiewicz S, Teegardin C, Whitney JD. Retrospective review of the reduction of oral pressure ulcers in mechanically ventilated patients: a change in practice. Crit Care Nurs Q. 2012;35(3):247-254.

38. Huang TT, Tseng CE, Lee TM, Yeh JY, Lai YY. Preventing pressure sores of the nasal ala after nasotracheal intubation: from animal model to clinical application. J Oral Maxillofac Surg. 2009;67(3):543-551.

39. Jacobson R, Tescher A, Miers A, Downer L. Improving practice: efforts to reduce occipital pressure ulcers. J Nurs Care Qual. 2008;23(3): 283-288. 
Chronic Wound Care Management and Research is an international, peer reviewed, open access, online journal publishing original research, reviews, editorials, and commentaries on the causes and management of chronic wounds and the major issues related to chronic wound management. Topics also include chronic wounds as comorbidities to other conditions, patient adherence to therapy, and the economic burden of chronic wounds. The manuscript management system is completely online and includes a very quick and fair peer review system, which is all easy to use. Visit http://www.dovepress.com/testimonials.php to read real quotes from published authors.

Submit your manuscript here: https://www.dovepress.com/chronic-wound-care-management-and-research-journal 